LETTERS

\section{A nation divided}

Corfield et al demonstrate improvements in door-to-needle time with a relatively simple organisational change. Other examples of innovation can be found across the country. ${ }^{2}$ Driving these changes in England and Wales is the National Service Framework which sets a standard of 60 minutes from calling for professional help until the initiation of thrombolysis. ${ }^{3}$ The Myocardial Infarction National Audit Project (MINAP) demonstrates the success of this approach. ${ }^{4}$

The only current standard which applies in Scotland is that set by Quality Improvement Scotland (QIS). This is a door-to-needle target of 30 minutes for the delivery of thrombolysis in the context of an acute ST elevation myocardial infarction. ${ }^{5}$ There is no standard set for call-to-needle and furthermore there is no national audit framework to monitor progress. In our own area although we achieve and exceed the current QIS target with a median door-to-needle time of 24 minutes for patients presenting to the Accident and Emergency department, if the National Framework target for call-toneedle is applied we would fail to achieve the standard by $27 \%$ (median call-to-needle time 76 minutes). We can see no reason why the prehospital phase of the treatment of acute myocardial infarction has been ignored by QIS. Without this as an audit standard, many departments simply do not collect the data, and the opportunity for local organisational change is lost.

If national targets are to affect the performance of the National Health Service, they need to be applied to the entire United Kingdom.

R J Cook, J Ronald, D K Pedley, W G Morrison Accident and Emergency Department, Ninewells Hospital and Medical School, Dundee, Scotland

Correspondence to: R J Cook, Accident and Emergency Department, Ninewells Hospital and Medical School, Dundee, Scotland; ronald.j.cook@ tuht.scot.nhs.uk

doi: $10.1136 / \mathrm{emj} .2005 .024448$

\section{References}

1 Corfield AR, Graham CA, Adams JN, et al. Emergency department thrombolysis improves door to needle times. Emerg Med $J$ 2004; 21:676-80.

2 Department of Health. Review of early thrombolysis. London: Department of Health, 2003, http://www.dh.gov.uk/assetRoot/04/ 06/82/51/04068251.pdf

3 Department of Health. National service framework for coronary heart disease. London: HMSO, 2000, 28-35. http://www.dh.gov.uk/ assetRoot/04/05/75/25/04057525.pdf

4 Royal College of Physicians of London. Myocardial infarction national audit project. London: Royal College of Physicians of London, 2004, www.rcplondon.ac.uk/pubs/books/ minap/index.htm (accessed 2 November 2005).

5 Clinical Standards Board for Scotland. Secondary prevention following ST elevation myocardial infarction. Edinburgh: Clinical Standards, 2000, 29-32.

http://www.show.scot.nhs.uk/sehd/

publications/cdtf/cdtf.pdf

\section{NICE head injury guidelines - expensive? Yes, but what are the alternatives?}

I read with some surprise Dr Leaman's article on the impact of the National Institute for Clinical Excellence (NICE) guidelines on a district general hospital. ${ }^{1}$ I am truly confused at the level of anxiety this topic is causing in the UK. In most other developed countries, the use of skull $x$ rays has long been abandoned in favour of the selected use of computed tomography (CT) scans in patients with head injuries. Although I appreciate the increased resource implications inherent in the implementation of these guidelines, I really do not see a viable alternative, apart from reliance on an outdated mode of investigation (skull $x$ ray) in what should be a first world setting. In our paediatric department, we started relying on a modified version of the American Academy of Pediatrics guidelines in 2001. The use of skull $x$ rays has fallen dramatically, although there has only been a modest rise in the use of CT scans in patients with minor head injuries.

I do agree with the Dr Leaman's point regarding out of hours scans, but we really have no firm evidence on which to base our assumption that patients requiring a scan can always wait until the morning. On the other hand, implementation of the NICE guidelines, along with careful audit will provide us with such data, at which time we can safely modify the guidelines to suit local practice. It is time that the UK falls into line with modern practice regarding the management of head injuries, even if this means an increase in the use of resources.

I Sammy

University of the West Indies, St Augustine, Trinidad and Tobago; psam@tstt.net.tt

doi: $10.1136 /$ emj.2005.024430

\section{Reference}

1 Leaman AM. The NICE guidelines for the management of head injury: the view from a district hospital. Emerg Med J 2004;21:400.

\section{ATLS: there are alternatives}

I was heartened by the courageous but constructive critique of the Advanced Trauma Life Support (ATLS) course by Driscoll and Wardrope. ${ }^{1}$ It promises an end to my lonely position as ATLS sceptic, which began in 1999 when I suggested that, although ATLS was "the greatest reformation in trauma care" in the late twentieth century, it was "an American solution in a British context" (your readers may have noticed the subsequent regrettable trend in which car occupants who are one minute squabbling vigorously about responsibility for a collision are the next abruptly straitjacketed in yellow plastic). I fretted that the Course was based on a dubious notion that trauma is a "surgical" disease, that it had become the New Dogma, and was suspiciously clubby ("I'm an ATLS instructor and you're not"). But my real concerns were that:
- The ATLS course arguably represents a major drain on scarce human and educational resources (How many days do consultants in emergency medicine spend away from their departments on these courses? How much is the NHS spending on the course fees?).

- ATLS only addresses the initial part of trauma care and is not a panacea (injury prevention and rehabilitation are at least as important).

- While evidence based medicine is something to which we all now aspire, the massive changes in the ATLS manual since its inception are a worrying illustration of the dearth of serious science underpinning what ATLS promotes.

I share Driscoll and Wardrope's disappointment at the continuing exclusion of emergency physicians from the development of ATLS. But happily, five years after I quit the NHS, the Royal College of Surgeons in Ireland has addressed my concerns with a set of clinical guidelines ${ }^{3}$ that I believe recognise the realities of trauma care in these islands.

May I invite your readers to peruse a document $^{3}$ which is by no means perfect, but which reflects their daily experience, along with that of their anaesthetic, surgical, and other colleagues? The sheer number of consultants and trainees in emergency medicine who contributed to this important document may reassure those of your readers who feel a little excluded by the ATLS "elite" that their contribution to trauma care is in fact incalculable. I hope it may also offer some encouragement to those who believe that there are other options in trauma care on this side of the Atlantic, and that emergency medicine will show the way.

C Luke Cork University Hospital, Cork, Ireland; chrisluke@eircom.net

doi: $10.1136 / \mathrm{emj} .2005 .025080$

\section{References}

1 Driscoll P, Wardrope J. ATLS: past, present, and future. Emerg Med J 2005:22:2-3.

2 Luke LC. ATLS: has the end become the means? CPD Anaesthesia 1999;1:94-6.

3 Clinical Guidelines Committee, Royal College of Surgeons in Ireland. Initial Management of the Severely Injured Patient, Dublin, November 2003. Available at: www.rcsi.ie/documents/ SEVERLYINJUREDGUIDELINES.pdf (accessed 2 November 2005).

\section{Auditory and visual prompts during cardiopulmonary resuscitation in the emergency department}

We read with interest Williamson et al's study on the use of audio prompts in automatic external defibrillators to improve cardiopulmonary resuscitation (CPR) in untrained and trained lay subjects. We report a study from an emergency department (ED) using trained ED staff (doctors and nurses) and paramedics. Through our own 